\title{
Relações psicotipológicas com base no ponto de vista de multilíngues falantes de português (L1), inglês (L2) e alemão (L3)
}

\author{
Aline Behling Duarte \\ PPGL/ Universidade Federal de Pelotas \\ alinebehlingduarte@gmail.com \\ Isabella Ferreira Mozzillo \\ Universidade Federal de Pelotas \\ isabellamozzillo@gmail.com \\ Bernardo Kolling Limberger \\ Universidade Federal de Pelotas \\ limberger.bernardo@gmail.com
}

\section{Resumo}

O objetivo deste estudo foi identificar a percepção de multilíngues falantes de português (L1), inglês (L2) e alemão (L3) sobre as relações psicotipológicas entre essas línguas. Com base nos trabalhos desenvolvidos por Hall et al. (2009), Lindqvist (2015) e Sánchez e Bardel (2016), um questionário de cunho psicotipológico foi elaborado. A utilização da tarefa considerava relações ortográficas, fônico-fonológicas e gramaticais que se estabelecem entre as línguas. Como hipóteses para o trabalho, considerávamos que os participantes avaliariam o par de línguas inglês-alemão, em termos gerais, como mais semelhante. Em relação aos aspectos ortográficos, presumíamos que o par português-alemão seria entendido como distante. Ainda, acreditávamos que em termos fônico-fonológicas, a combinação inglês-alemão fosse escolhida como mais próxima pelos participantes. No que tange à gramática das línguas, o par português-inglês seria compreendido como o mais próximo. Após a coleta e a análise dos dados obtidos, os resultados indicaram que as hipóteses levantadas condiziam com a maior parte das avaliações feitas, sendo a única exceção referente às regras sintáticas das línguas. De acordo com os participantes, a combinação inglês-alemão apresenta maiores semelhanças sintáticas e não o par português-inglês.

Palavras-chave: Multilinguismo. Tipologias linguísticas. Psicotipologia. 


\section{Abstract}

The aim of this study was to identify how multilingual speakers of Portuguese (L1), English (L2) and German (L3) perceived the psychotypological relationships among these languages. Based on the work developed by Hall et al. (2009), Lindqvist (2015) and Sánchez and Bardel (2016), a psychotypological questionnaire was developed. The purpose of using the task considered the participants' perceptions regarding the orthographic, phonic-phonological and grammatical relations, which are established among languages. As hypotheses for the study, we considered that the participants would access the English-German language pair, in general terms, as more similar. Regarding the orthographic aspects, we assumed that the Portuguese-German pair would be understood as distant. Still, we idealized that in phonic-phonological terms, the English-German combination was chosen as the closest by the participants. Regarding the grammar of languages, the Portuguese-English pair would be understood as the closest. After collecting and analyzing the data obtained, the results indicated that the hypotheses raised were in line with most of the assessments made, being the only exception regarding the syntax of languages. According to the participants, the English-German combination has greater syntactic similarities and not the Portuguese-English pair.

Keywords: multilingualism; linguistic typologies; psychotypology.

\section{Introdução}

Estudos voltados à psicotipologia têm despertado o interesse de pesquisadores, especialmente no cenário europeu. O termo "psicotipologia" foi cunhado por Kellerman (1983) com o intuito de dar conta das percepções que aprendizes de línguas tinham sobre as correspondências entre línguas. Estudos empíricos desenvolvidos por Hall et al. (2009), Lindqvist (2015) e Sánchez e Bardel (2016) são as principais bases para o desenvolvimento deste trabalho. Acreditamos que, com base nos resultados encontrados pelos autores, é possível compreender a necessidade de desenvolvimento de mais pesquisas relacionadas ao multilinguismo e às psicotipologias linguísticas com relação a diferentes configurações multilíngues. Encontramos somente um estudo brasileiro que investiga psicotipologia em multilíngues (BRITO, 2011). Esse estudo investiga a relação entre psicotipologia e influências translinguísticas na leitura em voz alta de aprendizes de alemão em contexto de imersão e salienta a 
importância de considerar as percepções psicotipológicas e as relações tipológicas na aprendizagem de uma língua estrangeira.

Nesta pesquisa, tivemos por objetivo identificar a percepção de multilíngues falantes de português (L1), inglês (L2) e alemão (L3) sobre as relações psicotipológicas entre essas línguas. Foram averiguadas as percepções de multilíngues falantes de português (L1), inglês (L2) e alemão (L3) em relação às proximidades e às distâncias linguísticas entre as línguas. À luz dos trabalhos elaborados pelos linguistas antes mencionados e da tipologia linguística, foram preditos os possíveis entendimentos que os participantes teriam sobre a relação entre as línguas analisadas. Inicialmente, consideramos que, tendo como base os níveis de proficiência, os participantes indicariam de forma objetiva que o par de línguas mais semelhantes seria o inglês-alemão. Em função do acesso mais facilitado à língua inglesa, acreditávamos que os participantes, todos brasileiros, julgariam ser mais fácil a aprendizagem dessa língua. Soma-se a isso a noção de que a gramática da língua alemã é complexa em virtude das declinações e a da língua inglesa é simples em função das poucas formas verbais. Quanto à ortografia das línguas, presumíamos que fosse entendido o pareamento português-alemão como o mais distante aos olhos dos informantes. Em relação aos aspectos fonético-fonológicos, imaginávamos que a combinação inglês-alemão fosse elencada como a mais próxima. Por fỉm, no que diz respeito às percepções acerca da estrutura sintática das línguas, consideramos que o pareamento portuguêsinglês fosse ser tido como o mais relacionado.

$\mathrm{Na}$ próxima seção, abordamos a distinção entre tipologia e psicotipologia. Em seguida, discutimos os resultados encontrados em pesquisas com multilíngues. $\mathrm{O}$ método utilizado na elaboração do questionário, a seleção dos participantes e a coleta de dados são apresentados na terceira seção. Na parte seguinte, são apresentados e discutidos os dados observados. Por fim, retomamos os resultados e abordamos as contribuições desta pesquisa para o desenvolvimento de futuros estudos voltados à área de psicolinguística. 


\section{$2 \mathrm{O}$ crescimento do multilinguismo e a terminologia da pesquisa com multilíngues}

A realidade multilíngue está presente ao nosso redor de muitas maneiras, e há diversos motivos para o crescimento do multilinguismo: processos migratórios, relações familiares, desejo de continuar os estudos, necessidade de comunicação com falantes de outras línguas, ambições profissionais ou turismo (SZUBKO-SITAREK, 2015). Atualmente, sabe-se que a maior parte das pessoas do mundo não é monolíngue, pois estas são falantes de duas ou mais línguas (GROSJEAN, 2008). Para Crystal (2011), a tendência que se apresenta atualmente dá indícios de que o fenômeno multilíngue ganhará cada vez mais espaço, fato que legitima o desenvolvimento de estudos voltados às relações que se estabelecem entre L1, L2 e L3.

Embora se perceba um aumento no interesse na temática multilíngue, ainda esbarramos em um problema de cunho terminológico quando se emprega a condição bilíngue para caracterizar quaisquer indivíduos que não sejam monolíngues (MYERS-SCOTTON, 2002; GROSJEAN, 2008). De Angelis (2007) critica essa conduta ao afirmar que, com a necessidade de expressar um novo conceito ou descrever um novo fenômeno, há uma tendência em tomar emprestada uma terminologia já empregada em campos bem estabelecidos e adaptá-la a um novo âmbito de pesquisa. Assim, diversos estudos acabam por igualar o bilinguismo ao multilinguismo ou consideram o multilinguismo mera extensão do bilinguismo. Pesquisadoras como, por exemplo, Cenoz (1997) e Butler e Hakuta (2013) defendem que ambos os termos não devem ser tidos como sinônimos. Para os autores, é primordial que sejam feitas distinções claras entres as duas configurações linguísticas.

Conforme defendem Butler e Hakuta (2013) e Cenoz (1997; 2013), há uma série de diferenças entre a aquisição bilíngue e a multilíngue. Butler e Hakuta (2013) destacam que o conhecimento que o multilíngue possui de duas ou mais línguas, a maior flexibilidade cognitiva, a consciência metalinguística desenvolvida e o uso de estratégias de aprendizagem já conhecidas pelo aprendiz fazem com que o processo de aquisição se torne mais complexo. Cenoz (2013) corrobora essa perspectiva ao salientar que aprendizes multilíngues estão equipados com uma bagagem linguística 
mais ampla e complexa, podendo, facilmente, relacionar novas estruturas, novo vocabulário ou novas formas de expressar funções comunicativas nas duas línguas que já conhecem, não apenas a uma delas, como no caso dos monolíngues. Com isso, os aprendizes podem utilizar certas estratégias para obter mais sucesso na aprendizagem de outras línguas.

Nesta proposta de estudo, adotamos a definição de McArthur (1992), que interpreta o multilinguismo como "a capacidade de usar três ou mais línguas, separadamente ou em vários graus de alternância de código"1 (p. 673). O multilinguismo é considerado uma configuração linguística complexa e dinâmica que envolve sempre uma terceira língua (L3) e outras línguas adicionais (DE ANGELIS, 2007; LIMBERGER, 2018). Também se parte do pressuposto defendido por Mozzillo (2001) de que bilíngues e, consequentemente, multilíngues -, mesmo sendo vistos como falantes altamente proficientes na(s) língua(s) estrangeira(s), em geral não apresentam o mesmo desempenho nas línguas em todos os contextos possíveis.

\section{Os estudos voltados à (psico)tipologia: o objetivo em contraste com o subjetivo}

Segundo Croft (2003), as línguas são agrupadas em classificações de tipologias, uma averiguação de cunho objetivo, que busca identificar características comuns às línguas. Conforme destacam Shibatani e Bynon (1999), os estudos sobre as tipologias linguísticas ganharam popularidade por volta de 1928. Todavia, conforme os autores, a tradição dos estudos tipológicos teve início com os estudos de Friedrich von Schlegel, com a publicação de Über die Sprache und Weisheit der Indier (Sobre a língua e a sabedoria dos indianos) em 1808.

Inicialmente, as pesquisas eram voltadas às classificações de natureza morfossintática, na qual as línguas eram estudadas de forma exaustiva e criteriosa. Nessa especialidade, destacou-se August Schleicher, em 1848, que identificou conexões entre as estruturas morfológicas e os

\footnotetext{
${ }^{1}$ No original: "The ability to use three or more languages, either separately or in various degrees of code-mixing".
} 
padrões pelos quais os aspectos gramaticais entre línguas eram expressos (SHIBATANI; BYNON, 1999). Assim, Luraghi (2017) esclarece que línguas cujas palavras consistem em apenas um morfema são classificadas como analíticas, ao passo que línguas que utilizam mais de um morfema nas palavras são catalogadas como sintéticas.

De acordo com Luraghi (2017), as línguas também podem ser tipologicamente classificadas de acordo com a ordem dos elementos em frases declarativas com verbos transitivos, a saber: sujeito (S), verbo (V) e objeto (O). Nesse caso, 95\% das línguas do mundo são basicamente dispostas em três categorias: SVO, SOV e VSO. Como exemplos temos inglês, japonês e árabe, respectivamente.

Uma visão mais abrangente analisa as línguas com base nas construções verbais cuja análise considera a sintaxe, a semântica e a lexicalização. Segundo Talmy (1991), precursor dessa linha de investigação, tipologicamente as línguas podem ser agrupadas em dois grupos, a saber: organizadas considerando a ideia de direção de movimento que o verbo denota (verb-framed) ou de forma exterior ao verbo (satelliteframed). Na estrutura verb-framed, as informações sobre o caminho de movimento são expressas por meio da raiz do verbo, como nas línguas românicas. Talmy (1991) utiliza a seguinte frase em espanhol como exemplo para esclarecer a construção: Terminé de escribir la carta. Por sua vez, na estrutura satellite-framed, as informações sobre um movimento são expressas fora do verbo, com o auxílio de partículas adverbiais, como é o exemplo das línguas germânicas. Em He ran into the room, é possível perceber que a partícula into completa o sentido da frase.

No que concerne aos estudos voltados às línguas estrangeiras abarcadas nesta pesquisa, Moravcsik (2013, p. 3) ressalta a existência de uma razão bastante simples para as semelhanças compartilhadas pelas línguas inglesa e alemã, a saber: há aproximadamente 2.500 anos, ambas as línguas não existiam separadamente, uma vez que foram derivadas, teoricamente, de um único ancestral - o protogermânico ou germânico comum. Podem ser notadas muitas similaridades ortográficas, como, por exemplo, house e Haus, "casa" em inglês e alemão, respectivamente. Quanto ao sistema fonológico do alemão e do inglês, da mesma forma podem ser notadas similaridades, pois essas palavras são pronunciadas de forma quase igual nas duas línguas. 
Nas comparações tipológicas, as estruturas sintáticas do alemão e do inglês também apresentam semelhanças. Moravcsik (2013, p. 68) exemplifica essa questão da seguinte forma: (1) Ich folge ihm (alemão) e (2) I follow him (inglês). A tradução adequada para as frases (1) e (2) é a mesma: "Eu o sigo". Conforme destaca a autora, é possível identificar a mesma ordem de elementos - sujeito, verbo e objeto -, assim ambas as frases recaem sob a categoria SVO. Moravcsik (2013, p. 94) aponta estruturas mais complexas que demonstram similaridades, caso de (4) Julia sah einen Hund im Garten (alemão) e (5) Julia saw a dog in the garden. Ambas as frases podem ser traduzidas como: "Julia viu um cachorro no jardim". Segundo defende a tipologista, há uma relação de proximidade entre as gramáticas do inglês e do alemão. A estrutura-padrão de ambas as línguas é SVO, tipologia nominativa-acusativa (EBERHARD; SIMONS; FENNIG, 2020). Entretanto, em alemão, conforme Duden (2005), há movimentos que enviam o verbo principal para o fim da sentença, resultando na estrutura SOV, como nas orações subordinadas, iniciadas por conjunções e pronomes, e, ainda, em sentenças formuladas com tempos verbais analíticos (como no Perfekt, tempo verbal passado). Essas especificidades podem causar a impressão nos aprendizes de que as línguas têm estruturas totalmente diferentes. Outras diferenças têm relação com a ortografia. Em alemão, por exemplo, um fonema simples é atribuído, em geral, de forma exata a um grafema (DUDEN, 2005). Com exceção de empréstimos e estrangeirismos, cada grafema representa um fonema, e cada fonema é representado por um grafema. Até mesmo os ditongos têm escrita transparente. Landerl, Wimmer e Frith (1997, p. 317) nos fornecem um exemplo com base nas vogais. O grafema "a" vale para a mesma vogal nas palavras Ball, Katze e Hand, ao passo que o mesmo grafema representa diferentes vogais nas palavras do inglês ball, cat e hand.

Diferentemente da tipologia linguística, a psicotipologia não está alicerçada em aspectos constatáveis por meio de comparações profundas e objetivas das estruturas das línguas. A noção de psicotipologia, cunhada por Kellerman (1993), está diretamente relacionada à percepção que os indivíduos têm sobre a proximidade ou a distância entre as línguas que falam. Dessa forma, essas relações de semelhança e de diferença estabelecidas pelos indivíduos não correspondem, necessariamente, às relações reais. Para Kellerman (1983), as influências às quais os aprendizes 
de línguas estrangeiras estão sujeitos - e que muitas vezes culminam em inexatidões linguísticas - nem sempre são provenientes de relações óbvias entre as línguas (p. 128), como sugerido pela Análise Contrastiva (LADO, 1957). Segundo Kellerman (1983), é com base nas observações de natureza metacognitiva que aprendizes desenvolvem suas próprias "noções de relações entre L1 e L2"2 (p. 113).

Kellerman (1983) defendeu que as noções estabelecidas pelos aprendizes funcionam como gatilhos para as influências translinguísticas e que a consciência linguística é uma importante fonte de monitoramento, controle e reajuste das línguas. No que diz respeito aos usuários das línguas, o estudioso ressalta que a consciência metalinguística se desenvolve mais rapidamente em falantes que já dominam ao menos duas línguas. À luz dos pressupostos de Kellerman (1983), podemos cogitar que falantes multilíngues possam ter maior clareza quanto às relações que se estabelecem entre as línguas, tipologicamente e psicotipologicamente, porque teriam uma consciência metalinguística mais desenvolvida do que bilíngues (CENOZ, 2013).

Ainda de acordo com Kellerman (1983), as percepções de proximidade e de distância entre as línguas não permanecem estáticas no entendimento dos aprendizes. Consequentemente, podemos acreditar que ao sofisticarem suas habilidades metacognitivas, por meio da maior exposição às línguas, isto é, à medida que seus níveis de proficiência aumentam, maiores são as chances de que a tipologia e a psicotipologia estejam de acordo.

No que remete às pesquisas voltadas aos estudos das percepções psicotipológicas dos aprendizes multilíngues, ainda são poucos os esforços desenvolvidos. Todavia, um ponto em comum aos estudos é a utilização de instrumentos similares, ou seja, questionários que visam a averiguar as interpretações dos informantes.

\footnotetext{
${ }^{2}$ No original: "notions of the relations between the L1 and L2" (KELLERMAN, 1983, p. 113).
} 


\section{As pesquisas sobre psicotipologia: a aplicação de questionários}

Apesar de não vir da mesma tradição dos estudos da tipologia linguística, o interesse pela psicotipologia pode ser evidenciado em trabalhos desenvolvidos especialmente no continente europeu, um contexto propício para o desenvolvimento de pesquisas sobre multilinguismo em função da proximidade geográfica entre países de línguas diversas.

Em Hall et al. (2009), foi desenvolvido um estudo com multilíngues falantes de espanhol (L1), inglês (L2), alemão e francês (L3). Com base na aplicação do questionário, os linguistas buscaram observar como as percepções dos aprendizes afetariam a aprendizagem de alemão e francês como línguas estrangeiras. Os resultados encontrados indicaram que os participantes julgavam o par de línguas inglês-alemão o mais próximo. Ainda, foi possível constatar que os mesmos informantes consideraram o par de línguas espanhol-francês o mais similar. Com base nos resultados, os estudiosos puderam verificar que os participantes julgavam ser menos desafiador aprender alemão após terem estudado inglês. Cabe destacar que os informantes também julgaram serem mais próximos os léxicos das línguas inglesa e francesa, línguas tipologicamente distantes, mas com um grande número de empréstimos lexicais.

Em Lindqvist (2015), a autora investigou as percepções de um grupo de 63 informantes falantes de sueco (L1), inglês (L2) e francês (L3) com idades variadas entre 12 e 16 anos. Em ambas as línguas estrangeiras, os informantes tinham uma média de sete anos de exposição, proveniente da escola. Aos informantes foi solicitado que escrevessem em francês todos os fatos que pudessem lembrar sobre uma história que lhes havia sido apresentada com imagens, sem o uso de nenhuma das línguas em particular. No que tange ao questionário de cunho psicotipológico, majoritariamente, ao levar em consideração aspectos gerais das três línguas, os informantes julgaram o inglês mais próximo do francês, em $75 \%$ das respostas. Ainda, $100 \%$ dos participantes acreditavam que a língua inglesa seria a mais facilmente aprendida em comparação à língua francesa. Levando em consideração aspectos gerais, 56\% dos participantes perceberam maiores semelhanças entre o par de línguas sueco-inglês. Contudo, em relação ao vocabulário das línguas, o par inglês-francês, em $43 \%$ das respostas, foi considerado mais próximo. Em referência aos 
aspectos sintáticos, os participantes julgaram o par sueco-inglês o mais similar, $63 \%$ das respostas. O resultado do teste aplicado evidenciou que os empréstimos lexicais foram $70 \%$ provenientes da L2, o inglês. Assim, a influência translinguística originou-se especialmente do par de línguas sueco-inglês, que foi julgado mais semelhante.

Em Sánchez e Bardel (2016), as autoras investigaram as relações entre psicotipologia e influências translinguísticas em dois grupos de 47 falantes multilíngues de espanhol e catalão (ambas L1), alemão (L2) e inglês (L3). Os informantes foram divididos em dois grupos: um composto por participantes de 10 a 12 anos e outro grupo, por participantes de 13 a 15 anos. Para o levantamento dos dados, as autoras optaram por utilizar o instrumento desenvolvido por Hall et al. (2009). Os participantes foram convidados a assistir a um recorte de dois minutos do filme Tempos modernos, de Charles Chaplin. Após a apresentação do vídeo, os informantes escutaram uma narrativa dos eventos feita por um falante nativo de língua inglesa. Em seguida, aos participantes foi solicitado que contassem a história com suas próprias palavras utilizando a L3, o inglês. No que se refere às proximidades e às distâncias entre as línguas, tanto o grupo mais jovem (97\%) quanto o grupo mais velho (80\%) consideraram o par de línguas alemão-inglês mais semelhante em termos gerais. Quanto às similaridades lexicais, ambos os grupos julgaram perceber maiores similaridades entre alemão-inglês. Todavia, o grupo mais jovem percebeu mais semelhanças de cunho sintático no par alemão-inglês, 74\% dos resultados. O grupo de aprendizes mais velhos indicou perceber maiores similaridades entre espanhol e inglês, em $65 \%$ das respostas. O resultado da tarefa de recontar a história revelou que os aprendizes mais jovens puderam verificar com maior acurácia as diferenças estruturais entre inglês e alemão. As autoras explicam esse resultado pautando-se nas diferenças cognitivas entre os dois grupos - os mais jovens teriam mais condições de separar as estruturas das línguas e reduzir as chances de transferências.

\section{Método}

Esta pesquisa tem base qualitativa, na qual os participantes foram convidados a responder a um questionário de percepções de proximidades e 
de distâncias linguísticas entre línguas (Anexo A), a saber: português (L1), inglês (L2) e alemão (L3). O questionário desenvolvido para este trabalho foi elaborado tendo como base pesquisas similares desenvolvidas por Hall et al. (2009), Sánchez e Bardel (2016) e Lindqvist (2015).

\subsection{Participantes}

Para a realização deste estudo contamos com dez multilíngues falantes de português (L1), inglês (L2) e alemão (L3), cuja média de idade era de 23 anos. Entre os participantes, seis eram do sexo masculino e quatro do sexo feminino. Todos eram alunos universitários ou tinham concluído a graduação recentemente. Nenhum dos participantes é ou era estudante dos cursos de Letras. Quanto às línguas que falam, os participantes listaram as línguas que fazem parte do estudo. Além disso, foram registradas línguas estrangeiras, como italiano, espanhol e japonês. Por acreditar que as línguas que não fazem parte do estudo não acarretariam obstáculos de análise, os participantes não foram excluídos da amostra. Os participantes autoavaliaram seus níveis de proficiência, sendo instruídos a utilizar uma escala de 1 a 6 ( 1 = muito baixo, 2 = baixo, 3 =razoável, $4=$ bom, $5=$ muito bom e $6=$ proficiente). Na Tabela 1 apresentamos as médias dos níveis de proficiência autoavaliada.

Tabela 1. Níveis de proficiência autoavaliada

\begin{tabular}{ccccc}
\hline & Leitura & Escrita & $\begin{array}{c}\text { Compreensão } \\
\text { auditiva }\end{array}$ & Fala \\
\hline Português & 6 & 6 & 6 & 6 \\
Inglês & 5,2 & 4,3 & 4,9 & 4,2 \\
Alemão & 2,4 & 1,8 & 2,3 & 1,9 \\
\hline
\end{tabular}

Fonte: elaboração dos autores

Os níveis de proficiência autoavaliada dos participantes refletem, de modo geral, que eles estudaram a língua alemã por um período relativamente curto, cerca de dois anos, tendo menos contato com essa língua do que com o inglês. 


\subsection{Procedimentos de coleta}

Para coletar os dados entramos em contato com uma professora de alemão da cidade de Pelotas para verificar a possibilidade de mediação entre os prováveis participantes e os pesquisadores. Em seguida houve o contato com os alunos de suas turmas, que foram convidados a participar da pesquisa, desde que fossem falantes das línguas que fazem parte do estudo. Após, foi informado o propósito do estudo e quais seriam suas partes. Dessa forma, aos participantes foi solicitado que assinassem um termo de consentimento livre e esclarecido, declarando estar cientes das etapas de coleta de pesquisa, manifestando concordância em participar do estudo e autorizando a utilização dos dados. Estes foram coletados em outubro de 2019. Foi solicitado que os participantes respondessem a dois questionários, explicitados a seguir.

\subsection{Instrumentos}

Foi solicitado que os participantes respondessem a um questionário de experiência e proficiência linguística (QuExPLi), adaptado de Scholl e Finger (2013). Por meio das informações provenientes dos participantes, puderam ser apurados dados como: sexo, idade, nível de escolaridade, línguas que falam e quais seus níveis de proficiência autoavaliada nas quatro habilidades linguísticas: leitura, escrita, compreensão auditiva e fala.

Com o objetivo de investigar como multilíngues falantes das línguas em análise concebiam as relações de proximidade ou distância, foi aplicada uma proposta preliminar ${ }^{3}$ de questionário de cunho psicotipológico (Anexo A) que abarca aspectos linguísticos voltados à ortografia, à gramática e à fonologia das línguas, aspectos linguísticos mais salientes para leigos. O instrumento utilizado contava com oito questões. Em duas delas os participantes deveriam justificar suas análises. Nas demais questões, deveria ser utilizada uma escala de 1 até 5 para a resposta $(1$ = muito pouco similares/diferentes, $2=$ pouco similares/diferentes, $3=$

\footnotetext{
${ }^{3} \mathrm{O}$ instrumento utilizado nesta pesquisa foi elaborado para que pudesse ser avaliada sua clareza e efetividade para investigar a psicotipologia na amostra do estudo.
} 
razoavelmente similares/diferentes, $4=$ similares/diferentes, $5=$ muito similares/diferentes).

Na próxima seção deste trabalho serão apresentados e discutidos os dados observados por meio da utilização do questionário de percepção de proximidades e de distâncias linguísticas.

\section{Resultados e discussão}

Para facilitar a compreensão dos dados apresentamos as percepções dos participantes em tabelas. Aos informantes foram dadas as opções que pareavam as três línguas analisadas no estudo. Eles julgaram, primeiramente, os pares de línguas que são, em geral, mais similares (Tabela 2). Como podemos verificar na tabela, apenas um dos informantes ponderou conter mais proximidades o par português-alemão.

Tabela 2. Número de julgamentos de similaridade linguística dos pares de línguas

Questão 1: De maneira geral, qual dos pares de línguas abaixo você acredita ser mais similar? $(\mathrm{n}=10)$

\begin{tabular}{ccc}
\hline português-inglês & português-alemão & inglês-alemão \\
0 & 1 & 9 \\
\hline
\end{tabular}

Fonte: elaboração dos autores

Pudemos verificar que, conforme o esperado, os informantes julgaram a combinação de línguas inglês-alemão como tendo, em termos gerais, mais similaridades. Entre as justificativas oferecidas pelos informantes que consideram o pareamento inglês-alemão como línguas mais próximas, um indicou que a proximidade geográfica como o motivo das semelhanças linguísticas. Ademais, um dos participantes indicou a correspondência sintática entre as línguas como um fator importante. $\mathrm{O}$ informante justificou sua asserção ao comparar as frases interrogativas "você é casado?": (5) are you married? e (6) bist du verheiratet?, inglês e alemão, respectivamente. O indivíduo chama atenção para a mesma ordem dos elementos nas frases (verbo auxiliar, sujeito e verbo). A explicação 
oferecida corrobora o postulado descrito por Moravcsik (2013) de que existem semelhanças sintáticas entre as línguas alemã e inglesa. Destacamos que um dos participantes indicou haver semelhanças entre as línguas em virtude da globalização da língua inglesa, que, dessa forma, acaba por tomar emprestadas muitas palavras de outras origens. Os demais seis participantes indicaram semelhanças lexicais e fonológicas como os motivos da sua percepção de similaridade.

No entanto, um participante julga o par de línguas portuguêsalemão mais similar. De acordo com a justificativa apresentada, o participante considera que as línguas tenham a mesma origem - o latim. Talvez essa percepção tenha relação com a ênfase dada às declinações no ensino. Conforme destaca Moravcsik (2013), tanto o inglês quanto o alemão são derivados do protogermânico, apesar de ambas as línguas terem sofrido forte influência latina.

Perguntamos também sobre a facilidade de aprendizagem em uma das línguas estrangeiras para verificarmos a relação entre psicotipologia e aprendizagem. Como esperávamos, a maior parte dos informantes considera ser menos desafiador aprender inglês (Tabela 3).

Tabela 3. Número de julgamentos de facilitação na aprendizagem de outras línguas por falantes de português como L1

Questão 2: Para um aprendiz cuja primeira língua é o português, qual das línguas abaixo seria mais fácil de aprender? $(\mathrm{n}=10)$

\begin{tabular}{cc}
\hline inglês & alemão \\
7 & 3 \\
\hline
\end{tabular}

Fonte: elaboração dos autores

Um dos informantes julga que tanto o português quanto o inglês são línguas estruturalmente simples e, em função desse aspecto, o inglês é mais acessível. Outro informante justifica ter optado pelo inglês, no entanto considera que ambas as línguas podem ser facilmente aprendidas por compartilharem muitas similaridades sintáticas com o português. Um informante utilizou frases de ordenação SVO para exemplificar sua posição, ou seja, fez uso da tipologia das línguas, conforme apontado por Luraghi (2017), para fundamentar sua argumentação. Outro aspecto 
destacado pelos informantes foi a questão do contato cultural ao qual estamos expostos diariamente. $\mathrm{O}$ acesso ao inglês é muito maior. Para o participante, aprender a língua inglesa torna-se mais simples em virtude dessa ótica. As justificativas apresentadas pelos informantes que defenderam ser mais fácil aprender alemão foram de cunho fonológico, pois percebem mais resquícios da língua portuguesa na pronúncia das palavras em alemão. Essa percepção pode ter relação com os cognatos de origem latina e com a pronúncia mais transparente que a do inglês (DUDEN, 2005; LANDERL; WIMMER; FRITH, 1997).

A seguir, apresentamos e discutimos os resultados das percepções psicotipológicas de cada um dos níveis linguísticos investigados.

\subsection{Nível ortográfico}

Os dados obtidos em relação às similaridades e às diferenças entre as relações ortográficas que podem ser estabelecidas entre as línguas estudadas podem ser observados nas Tabelas 4 e 5.

Tabela 4. Médias da percepção de semelhanças ortográficas entre as línguas (escala: $1-5)$

\begin{tabular}{lcc}
\hline $\begin{array}{l}\text { Questão 3: Quanto às semelhanças } \\
\text { ortográficas, em qual par de línguas } \\
\text { você percebe mais similaridades? }\end{array}$ & português-inglês & 2,4 \\
$\begin{array}{l}\text { Circule em uma escala de 1 a } 5 \\
\text { como você considera que os } \\
\begin{array}{l}\text { aspectos das duas línguas são } \\
\text { similares. }\end{array}\end{array}$ & português-alemão & 1,7 \\
\hline
\end{tabular}

\section{Fonte: elaboração dos autores}

De acordo com as percepções dos participantes, a combinação de línguas inglês-alemão apresenta maiores semelhanças. Esse resultado está de acordo com o que pôde ser observado na Tabela 1, que indica o nível de proficiência autoavaliada maior na leitura em ambas as línguas estrangeiras. Dessa forma, os participantes conseguem refletir de modo mais objetivo sobre proximidade lexical. Em muitos casos há intercompreensão entre inglês e alemão na leitura. Cabe destacar que o 
efeito averiguado está em consonância com os dados encontrados por Sánchez e Bardel (2016) quando seus informantes falantes de espanhol e catalão (L1), alemão (L2) e inglês (L3) também julgaram observar maiores semelhanças nas línguas estrangeiras de origem germânica. Os dados do julgamento das diferenças têm relação com os dados das semelhanças, ou seja, o par linguístico português-alemão foi considerado, em média, o mais distante e o menos semelhante.

Tabela 5. Médias da percepção de diferenças ortográficas entre as línguas (escala: 1-5)

Questão 4: Quanto às semelhanças português-inglês 3,5 ortográficas, em qual par de línguas você percebe mais diferenças?

Circule em uma escala de 1 a 5 como você considera que os aspectos das duas línguas são diferentes.

português-alemão

inglês-alemão 2,3

\section{Fonte: elaboração dos autores}

As maiores diferenças ortográficas foram indicadas no par português-alemão. Talvez a percepção de que ambas as línguas sejam ortograficamente mais distantes esteja atrelada à ocorrência, em alemão, de diacríticos, como o trema (ä, ö e ü) da letra Esszet (ß) e de encontros consonantais (Pf-, schw-, schl-, zw-, entre muitos outros).

\subsection{Nível fonético-fonológico}

Os dados obtidos em relação às similaridades e às diferenças entre as relações fonético-fonológicas que podem ser estabelecidas entre as línguas estudadas podem ser observados nas Tabelas 6 e 7. 
Tabela 6. Médias da percepção de similaridades fonético-fonológicas entre as línguas (escala: 1-5)

\begin{tabular}{lcc}
\hline $\begin{array}{l}\text { Questão 5: Quanto à pronúncia das } \\
\text { palavras, em qual par de línguas } \\
\text { você percebe mais similaridades? }\end{array}$ & português-inglês & 1,8 \\
$\begin{array}{l}\text { Circule em uma escala de 1 a 5 } \\
\text { como você considera que os } \\
\begin{array}{l}\text { aspectos das duas línguas são } \\
\text { similares. }\end{array}\end{array}$ & português-alemão & 2,4 \\
& inglês-alemão & 3,2 \\
\hline
\end{tabular}

\section{Fonte: elaboração dos autores}

Podem ser observadas maiores semelhanças fonético-fonológicas entre a combinação inglês-alemão e as menores entre o par portuguêsinglês. Cabe mencionar que alguns dos informantes defenderam a proximidade linguística de português-alemão justamente em relação à pronúncia das línguas por serem mais transparentes em relação à escrita. No entanto, ao avaliar a questão 1 do questionário, que perguntava sobre as similaridades em geral, os resultados obtidos mostram outro entendimento, uma vez que os valores observados entre português-inglês e portuguêsalemão são muito aproximados, conforme se nota na Tabela 7. É possível acreditar que esse resultado possa de alguma forma estar vinculado ao fato de a habilidade de fala ser uma das menos desenvolvidas nos participantes, como se pode verificar nos resultados da proficiência autoavaliada.

Tabela 7. Médias da percepção de diferenças fonológicas entre as línguas (escala: 1-5)

Questão 6: Quanto à pronúncia das palavras, em qual par de línguas você percebe mais diferenças?

Circule em uma escala de 1 a 5 como você considera que os aspectos das duas línguas são diferentes. 4
português-inglês
português-alemão
inglês-alemão

Fonte: elaboração dos autores 
Relações psicotipológicas com base no ponto de vista de multilíngues...

\subsection{Nível sintático}

Os dados obtidos em relação às similaridades e às diferenças entre os aspectos sintáticos que podem ser estabelecidas entre as línguas estudadas podem ser observados nas Tabelas 8 e 9.

Tabela 8. Médias da percepção de similaridades sintáticas entre as línguas (escala: 1-5)

Questão 7: Em relação aos aspectos gramaticais, em qual par de línguas você percebe mais similaridades? português-inglês

português-alemão

inglês-alemão
2,2

2

3,2

\section{Fonte: elaboração dos autores}

Tabela 9. Médias da percepção de diferenças sintáticas entre as línguas (escala: 1-5)

Questão 8: Em relação aos aspectos gramaticais, em qual par de línguas você percebe mais diferenças?

$\begin{array}{cc}\text { português-inglês } & 3,4 \\ \text { português-alemão } & 3,6 \\ \text { inglês-alemão } & 2,7\end{array}$

Fonte: elaboração dos autores

De acordo com as impressões dos informantes, existem maiores similaridades sintáticas entre o pareamento inglês-alemão e maiores diferenças (Tabela 9) na combinação português-alemão. Assumimos que essa avaliação está de acordo com os estudos da tipologia linguística (LURAGHI, 2017; MORAVCSIK, 2013; TALMY, 1991). A acurácia do julgamento pode estar relacionada ao fato de, em muitos casos, as aulas de línguas estrangeiras frisarem muito mais os aspectos sintáticos das línguas, fazendo com que os aprendizes desenvolvam certo grau de consciência sintática. O resultado averiguado ratifica os resultados observados por Lindqvist (2015), no qual falantes multilíngues de sueco (L1), inglês (L2) e francês (L3) também consideraram línguas de origem protogermânicas as mais próximas sintaticamente. 


\section{Considerações finais}

Ao analisarmos as respostas emitidas pelos participantes multilíngues falantes de português (L1), inglês (L2) e alemão (L3), foi possível validar a maior parte das hipóteses. De modo geral, a combinação inglês-alemão foi julgada a mais próxima. No que se refere à facilidade em aprender uma das línguas estrangeiras, sete dos dez participantes acreditam que seria mais fácil aprender inglês. Quanto às semelhanças ortográficas entre as línguas, constatamos que os participantes julgaram os pares português-inglês e inglês-alemão como as que compartilham maiores similaridades. Em relação aos aspectos de caráter fonético-fonológico, a combinação inglês-alemão foi apontada como a mais próxima. Em termos sintáticos, o pareamento alemão-inglês foi considerado o mais próximo.

No que se refere às limitações encontradas no desenvolvimento desta pesquisa, contamos com um número limitado de participantes. A dificuldade em contatar o público-alvo e a amostra muito específica mostraram-se fatores que dificultaram um pouco o desenvolvimento do trabalho. Quanto ao questionário psicotipológico, acreditamos que o testepiloto retratado neste artigo serve como um bom indicador de quais aspectos devem ser aprimorados para futuras pesquisas.

Espera-se que com o desenvolvimento do trabalho proposto possamos, em algum grau, fomentar estudos voltados às relações de interdependência entre múltiplas línguas, dada a escassez de trabalhos voltados ao assunto no Brasil. Com cerca de 210 línguas faladas no Brasil (OLIVEIRA, 2008), acreditamos haver um campo inexplorado quanto às inúmeras combinações de línguas que podem ser investigadas. Ademais, é inegável a necessidade de estabelecer a pesquisa multilíngue como uma área de estudo própria para que possam ser desenvolvidos estudos que não se baseiem apenas em trabalhos sobre o bilinguismo, tendência vista atualmente. Julga-se que existem ferramentas para alcançar esses objetivos e evidenciar os aspectos positivos do multilinguismo, bem como distanciar esse campo de pesquisa da já solidificada área bilíngue.

Ao pensarmos nas implicações pedagógicas de estudos sobre psicotipologia e multilinguismo para o ensino de línguas estrangeiras, entendemos que a falta de flexibilidade quanto à definição de quem pode ser considerado multilíngue incentiva a criação de barreiras no que se refere 
à valorização do fenômeno multilíngue. Brito (2011) salienta que a comparação dos aprendizes aos nativos das línguas pode afetar gravemente a maneira como o indivíduo entende sua aprendizagem. Equiparar falantes nativos a estrangeiros pode afetar a continuidade da aprendizagem de maneira que seja invalidado todo o esforço e dedicação empregados no processo de aquisição. Além disso, acaba-se por não reconhecer o conhecimento linguístico que o indivíduo já possui. Para potencializar a aprendizagem de língua estrangeira, todo conhecimento linguístico prévio deve ser considerando

\section{Referências}

BRITO, K. S. Influências interlinguísticas na mente multilíngue: perspectivas psicolinguísticas e (psico)tipológicas. 2011. 274 f. Tese (Doutorado em Estudos Linguísticos) - Programa de Pós-Graduação em Estudos Linguísticos, Universidade Federal do Paraná, Curitiba, 2011.

BUTLER, Y.; HAKUTA, K. Bilingualism/multilingualism and second language acquisition. In: BHATIA, T. K.; RITCHIE, W. C. (Ed.). The handbook of bilingualism and multilingualism. Hoboken: John Wiley \& Sons, 2013. p. 114-144.

Disponível em: https://doi.org/10.1002/9780470756997.ch5

CENOZ, J. The influence of bilingualism on multilingual acquisition: some data from the Basque Country. In: Anais do Simpósio Internacional sobre o Bilinguismo, Universidade de Vigo, 21-25 de outubro, 1997, p. 278-287.

CENOZ, J. The influence of bilingualism on third language acquisition: Focus on multilingualism. Language Teaching, v. 46, n. 1, p. 71-86, 2013. Disponível em: https://doi.org/10.1017/S0261444811000218

CROFT, W. Typology and universals. London: Cambridge University, 2003. Disponível em: https://doi.org/10.1017/CBO9780511840579 
CRYSTAL, D. From the world to the word - and back again. Disponível em: Disponível em: http://www.davidcrystal.com. Acesso em: 31 out. 2019.

DE ANGELIS, G. Third or additional language acquisition. Dublin: Multilingual Matters, 2007. Disponível em: https://doi.org/10.21832/9781847690050

DUDEN. Die Grammatik: Unentbehrlich für richtiges Deutsch. Mannheim: Dudenverlag, 2005.

EBERHARD, D. M.; SIMONS, G. F.; FENNIG, C. D. (Ed.). Ethnologue: languages of the world. Twenty-third edition. Dallas: SIL International. Disponível em: http://www.ethnologue.com. Acesso em: 30 jul. 2020.

GROSJEAN, F. Bilinguismo individual. Tradução de Heloísa Augusta Brito de Mello e Dilys Karen Rees. Revista UFG, ano X, v. 5, p. 163-176, 2008.

HALL, C.; NEWBRAND, D.; ECKE, P.; SPERR, U.; MARCHAND, V.; HAYES, L. Learners' Implicit Assumptions About Syntactic Frames in New L3 Words: The Role of Cognates, Typological Proximity, and L2 Status. Language Learning, v. 59, n. 1, p. 153-202, 2009. Disponível em: https://doi.org/10.1111/j.1467-9922.2009.00503.x

KELLERMAN, E. Now you see it, now you don't. In: GASS, S.; SELINKER, L. (Ed.) Language transfer in language learning. Rowley: Newbury House, 1983. p. 112-134.

LADO, R. Linguistics across cultures. Ann Arbor: University of Michigan Press, 1957.

LANDERL, K.; WIMMER, H.; FRITH, U. The impact of orthographic consistency on dyslexia: A German-English comparison. Cognition, v. 63, n. 3, p. 315-334, 1997. Disponível em: https://doi.org/10.1016/S0010$\underline{0277(97) 00005-X}$ 
Relações psicotipológicas com base no ponto de vista de multilíngues...

LIMBERGER, B. K. Processamento da leitura e suas bases neurais: um estudo sobre o hunsriqueano. 2018. 269 f. Tese (Doutorado em Letras) Programa de Pós-Graduação em Letras, Pontifícia Universidade Católica do Rio Grande do Sul, Porto Alegre, 2018. Disponível em: https://doi.org/10.13140/RG.2.2.28790.42563

LINDQVIST, C. Do learners transfer from the language they perceive as most closely related to the L3? The role of psychotypology for lexical and grammatical crosslinguistic influence in French L3. In: DE ANGELIS, G.; JESSNER, U.; KRESI, M. (Ed.). Crosslinguistic influence and crosslinguistic interaction in multilingual language learning. London: Bloomsbury Academic, 2015. p. 231-251.

LURAGHI, S. Typology and historical linguistics. In: AIKHENVALD, A.; DIXON, J. (Ed.). The Cambridge Handbook of Linguistic Typology. Cambridge: Cambridge University Press, 2017, p. 95-123. Disponível em: https://doi.org/10.1017/9781316135716.004

MCARTHUR, T. Multilingualism. In: MCARTHUR, T. The Oxford Companion to the English Language. Oxford: Oxford University Press, 1992. p. 673.

MORAVCSIK, E. Introducing language typology. Cambridge: Cambridge University Press, 2013. Disponível em: https://doi.org/10.1017/CBO9780511978876

MOZZILLO, I. A conversação bilíngue dentro e fora da sala de aula de língua estrangeira. In: HAMMES, W.; VETROMILLE-CASTRO. R. (Org.) Transformando a sala de aula, transformando o mundo: ensino e pesquisa em língua estrangeira. Pelotas: Educat, 2001. p. 289-325.

OLIVEIRA, G. M. Plurilinguismo no Brasil. Brasília: Representação da Unesco no Brasil/Ipol, 2008. Disponível em: http://unesdoc.unesco.org/images/0016/001611/161167por.pdf. Acesso em: 31 out. 2019. 
MYERS-SCOTTON, C. Introduction. In: MYERS-SCOTTON, C. (Ed.). Contact linguistics. Oxford: Oxford University Press, 2002. p. 1-29. Disponível em: https://doi.org/10.1093/acprof:oso/9780198299530.003.0001

SÁNCHEZ, L.; BARDEL, C. Cognitive factors, linguistic perceptions and transfer in third language learning. Revue Française de Linguistique Appliquée, v. 21, n. 2, p. 123-138, 2016. Disponível em: https://doi.org/10.3917/rfla.212.0123

SCHOLL, A.; FINGER, I. Elaboração de um questionário de histórico da linguagem para pesquisas com bilíngues. Nonada: Letras em Revista, v. 2, n. 21, p. 21- 39, 2013.

SHIBATANI, M.; BYNON, T. Approaches to language typology: a conspectus. In: SHIBATANI, M.; BYNON, T. (Ed.). Approaches to language typology. Oxford: Oxford University Press, 1995. p. 01-26.

SZUBKO-SITAREK, W. Beyond bilingualism: issues in multilingualism. In: SZUBKO-SITAREK, W. Multilingual lexical recognition in the mental lexicon of third language users. Springer: London, 2015. p. 0132. Disponível em: https://doi.org/10.1007/978-3-642-32194-8

TALMY, L. Path to realization: a typology of event conflation. Proceedings of the seventeenth annual meeting of the Berkeley Linguistics Society: general session and parasession on the grammar of event structure, 1991. p. 480-519. Disponível em: https://doi.org/10.3765/bls.v17i0.1620 
Relações psicotipológicas com base no ponto de vista de multilíngues...

\section{Anexo A - Questionário Psicotipológico}

Data:

Participante n.:

Data de nascimento: Local de nascimento:

Leia as perguntas abaixo e as responda de maneira fiel às suas percepções quanto às relações estabelecidas entre as línguas. Fique ciente de que não há resposta certa ou errada.

1) De maneira geral, qual dos pares de línguas abaixo você acredita serem mais similares?

$\square$ Português-inglês $\square$ português-alemão $\square$ inglês-alemão

Justifique e dê exemplos:

2) Para um aprendiz cuja primeira língua é o português, qual das línguas abaixo seria mais fácil de aprender?

$\square$ inglês

$\square$ alemão

Justifique e dê exemplos:

3) Quanto às semelhanças ortográficas, em qual par de línguas você percebe mais similaridades? Circule em uma escala de 1 a 5 como você considera que os aspectos das duas línguas são similares $(1=$ muito pouco similares, 2 = pouco similares, 3 = razoavelmente similares, $4=$ similares; $5=$ muito similares)

português-inglês

português-alemão

inglês-alemão

$\begin{array}{lllll}1 & 2 & 3 & 4 & 5 \\ 1 & 2 & 3 & 4 & 5 \\ 1 & 2 & 3 & 4 & 5\end{array}$


4) Quanto às semelhanças ortográficas, em qual par de línguas você percebe mais diferenças? Circule em uma escala de 1 a 5 como você considera que os aspectos das duas línguas são diferentes ( 1 = muito pouco diferentes, 2 = pouco diferentes, 3 = razoavelmente diferentes, $4=$ diferentes; 5 = muito diferentes)

$$
\begin{aligned}
& \text { português-inglês } \\
& \text { português-alemão } \\
& \text { inglês-alemão }
\end{aligned}
$$

$\begin{array}{lllll}1 & 2 & 3 & 4 & 5 \\ 1 & 2 & 3 & 4 & 5 \\ 1 & 2 & 3 & 4 & 5\end{array}$

5) Quanto à pronúncia das palavras, em qual par de línguas você percebe mais similaridades? Circule em uma escala de 1 a 5 como você considera que os aspectos das duas línguas são similares $(1=$ muito pouco similares, 2 = pouco similares, $3=$ razoavelmente similares, $4=$ similares; $5=$ muito similares)

português-inglês
português-alemão
inglês-alemão

$\begin{array}{lllll}1 & 2 & 3 & 4 & 5 \\ 1 & 2 & 3 & 4 & 5 \\ 1 & 2 & 3 & 4 & 5\end{array}$

6) Quanto à pronúncia das palavras, em qual par de línguas você percebe mais diferenças? Circule em uma escala de 1 a 5 como você considera que os aspectos das duas línguas são diferentes $(1=$ muito pouco diferentes, $2=$ pouco diferentes, 3 = razoavelmente diferentes, $4=$ diferentes; $5=$ muito diferentes)

$$
\begin{aligned}
& \text { português-inglês } \\
& \text { português-alemão } \\
& \text { inglês-alemão }
\end{aligned}
$$

$\begin{array}{lllll}1 & 2 & 3 & 4 & 5 \\ 1 & 2 & 3 & 4 & 5 \\ 1 & 2 & 3 & 4 & 5\end{array}$

7) Em relação aos aspectos gramaticais, em qual par de línguas você percebe mais similaridades? $(1=$ muito pouco similares, $2=$ pouco similares, 3 = razoavelmente similares, $4=$ similares; $5=$ muito similares)

português-inglês

português-alemão

inglês-alemão

$\begin{array}{lllll}1 & 2 & 3 & 4 & 5 \\ 1 & 2 & 3 & 4 & 5 \\ 1 & 2 & 3 & 4 & 5\end{array}$


Relações psicotipológicas com base no ponto de vista de multilíngues...

8) Em relação aos aspectos gramaticais, em qual par de línguas você percebe mais diferenças? Circule em uma escala de 1 a 5 como você considera que os aspectos das duas línguas são diferentes $(1=$ muito pouco diferentes, 2 = pouco diferentes, $3=$ razoavelmente diferentes, $4=$ diferentes; 5 = muito diferentes)

$\begin{array}{llllll}\text { português-inglês } & 1 & 2 & 3 & 4 & 5 \\ \text { português-alemão } & 1 & 2 & 3 & 4 & 5 \\ \text { inglês-alemão } & 1 & 2 & 3 & 4 & 5\end{array}$

Recebido em: 31/07/2020

Aceito em: 09/12/2020

Title: Psychotypological relations from the standpoint of multilingual speakers of Portuguese (L1), English (L2) and German (L3) 